\title{
Welfare solidarities in the age of mass migration: evidence from European Social Survey 2016
}

\author{
Dimitri Gugushvili ${ }^{1} \cdot$ Laura Ravazzini $^{2,3}$ - Michael Ochsner ${ }^{5,6} \cdot$ Martin Lukac $^{4}$. \\ Orsolya Lelkes $^{7} \cdot$ Marcel Fink $^{8} \cdot$ Peter Grand $^{8} \cdot$ Wim van Oorschot $^{9}$
}

Accepted: 10 December 2020 / Published online: 6 January 2021

(c) The Author(s) 2021

\begin{abstract}
Welfare opinion research has traditionally viewed migration as a potential hazard for welfare solidarity. In this article, we argue that while increased presence of foreigners can indeed make some people less supportive of public welfare provision in general or trigger opposition to migrants' social rights, the link between migration and solidarity is not universally a negative one. Instead, many people can combine support for migration with high preferences for comprehensive social protection; others can endorse migration while they are not particularly supportive of an all-encompassing welfare state. Based on this line of reasoning we construct a taxonomy of four ideal types of welfare solidarity that are present in contemporary European welfare states. To illustrate the usefulness of this heuristic tool, we apply Latent Class Factor Analysis to European Social Survey round 8 data. We find that the majority of Europeans (56\%) combine strong support for both migration and the welfare state (extended solidarity). However, exclusive solidarity is also widely spread as over a quarter of respondents (28\%) oppose migration while expressing strong support for the welfare state. People who oppose migration and have relatively low preference for the welfare state (diminished solidarity) represent a small minority (5\%). A little more than a tenth (11\%) of Europeans endorse migration, but express relatively low support for the welfare state, which we assume to be a reflection of cosmopolitan solidarity. Despite considerable variation in the incidence of the four solidarities across countries, the preference structure is the same for all. Further, we find that at the individual level, the propensity to hold one of these types of solidarities is influenced by social trust, citizenship and country of birth, financial situation, education, and residence type. However, the extent of migration and social spending do not appear to be related with the propensity of holding either type of solidarity as the liberal's dilemma and the welfare chauvinism theories would predict.
\end{abstract}

Keywords Welfare solidarity $\cdot$ Taxonomy $\cdot$ Europe $\cdot$ Migration $\cdot$ Welfare spending

Laura Ravazzini

laura.ravazzini@unine.ch

Extended author information available on the last page of the article 


\section{Introduction}

Until recently, welfare solidarity was by and large a national phenomenon in Europe. Old-age pensions, sickness and disability insurance, unemployment benefits, family transfers and social services represented an embodiment of institutionalised forms of national solidarity as they were designed to redistribute resources (Kymlicka 2015; Swaan 1992). These services were financed through taxes or by social insurances, therefore redistributing both horizontally, i.e. across the life cycle, and vertically, i.e. from rich to poor. The aim of those welfare systems was to meet the needs of fellow citizens when they experienced various types of contingencies.

In the light of globalisation, and especially increasing migration, national welfare solidarity as the cornerstone of European welfare states is challenged. With European countries growing more and more culturally diverse, it is increasingly evident that maintaining broad support for welfare programmes also necessitates a rather strong sense of solidarity towards migrants-a concern for their wellbeing and a willingness to share resources traditionally confined to natives. However, the present welfare state scholarship is generally sceptical about such extended solidarity; instead, migration is analysed as a potential threat for the support for the welfare state. In this respect, two seemingly competing theories are particularly important: the 'liberal's dilemma' and 'welfare chauvinism'. The first states that the welfare state bases on strong solidarity with fellow citizens which is compromised when societies become more diverse. As a result, support for the welfare state is undermined among natives. Thus, liberal politicians (or in European context, social-democrats), as champions of universal social rights, are torn between preference for a strong welfare system or for openness towards migrants in order not to lose their core electorate, hence the name 'liberal's dilemma'. The second, welfare chauvinism theory, states that people do not like to share resources with 'outsiders', but they do want to maintain benefits they are accustomed to. Hence, they are against opening the welfare system to migrants (or even against migration in general). Both theories assume a negative relationship between migration and welfare. So far, they have been tested separately and the evidence is mixed.

In this article, we argue that in the age of mass migration, a unidimensional approach of testing the presence of a negative link between migration and welfare solidarity is not sufficient to capture the complex relation between the two phenomena. Certainly, we do acknowledge that an influx of sizable numbers of foreigners can lead to a 'diminished solidarity' (manifest in opposition to migration and relatively low support for the welfare state) or to an 'exclusive solidarity' (reflected in a combination of strong welfare preferences alongside opposition to migration and migrants' social rights) among some people. However, we propose that migration can also lead to an 'extended solidarity', whereby people simultaneously express preference for a strong welfare state and a concern and support for migrants. Furthermore, there are a number of solid theoretical reasons for why some people will endorse migration even though they are not particularly 
in favour of a strong welfare state. We term this as a 'cosmopolitan solidarity'. In sum, we propose a four-fold typology of welfare solidarity as a more complete heuristic tool to understand the relation between migration and welfare solidarity. To demonstrate its usefulness, we apply Latent Class Factor Analysis to European Social Survey round 8 data. Furthermore, we explore how the prevalence of the four ideal types of solidarity varies across the countries. We then use multilevel multinomial models to show how the individual propensity to belong to one of these solidarity groups is related to a range of individual-level socio-economic factors. Finally, we test the two theories, the liberal's dilemma and the welfare chauvinism, regarding their hypotheses on the effects of country-level factors on the interaction of attitudes towards migration and the welfare state.

The article is structured as follows: we first review the theories and the literature that link solidarity and migration and develop the four-fold taxonomy of solidarity. Next we formulate several hypotheses to be tested empirically. Then we explain the data and the methodology that we apply. The next section presents the results of data analysis and the conclusion section sums up the key findings.

\section{Solidarity and migration: theory and evidence}

Accentuated by pressure created in the aftermath of the 2008 financial crisis, increasing migration challenges national welfare states all over Europe. Migration can be seen as a particular risk for the principle of solidarity upon which all modern welfare states are based. According to this principle, a welfare state's society should be characterised by a positive bond between the fates of different people (de Beer and Koster 2009, p. 15). This positive bond might be driven by self-interests (do ut des) or/and by ideological beliefs, such as the support for the values of justice and reciprocity (unus pro omnibus, omnes pro uno). The welfare state can thus be perceived as an extensive form of organised and compulsory solidarity.

While support for the welfare state for a long time meant solidarity with fellow vulnerable citizens (e.g. the poor, the sick, the unemployed, and the elderly, see Baldwin 1990) or with citizens with high compulsory expenditures (e.g. families with children, see the new social risks identified by Taylor-Gooby 2004 and Bonoli 2006), nowadays it also necessitates feelings of solidarity with migrants. This new reality poses questions on the welfare deservingness of migrants as they did not spend their whole (working) life in the country.

The present literature offers two main theoretical perspectives regarding how Europeans' attitudes towards the welfare state may relate to increasing migration flows: the liberal's dilemma and welfare chauvinism. The first argues that a strong sense of solidarity and trust in fellow citizens is the cornerstone of the welfare state as it requires people to regularly pay large portions of their income to finance welfare entitlements from which they themselves may never benefit directly (such as social assistance and unemployment benefits) or will do so only after many decades of contribution (such as old-age pensions, see e.g. Goodhart 2004; Kymlicka and Banting 2006). In the face of large-scale migration and resulting increased heterogeneity of European societies support for the welfare state plummets as native citizens 
become less willing to share resources with people with whom they do not identify and whom they distrust. The typical argument refers to the USA, where racial heterogeneity is theorised to have deterred the development of a European-style comprehensive welfare state (Alesina and Glaeser 2004; Gilens 1999). Another strand of argumentation states that people may also become less sympathetic to the welfare state if they think that it attracts migrants (for 'welfare magnet theory' see Borjas 1999). Hence, it is proposed that progressive politicians in European welfare states are confronted with a trade-off between supporting either a generous welfare state or migration, commonly referred to as the 'New Liberal Dilemma' or 'Progressives' Dilemma' (Goodhart 2004; Kulin et al. 2016; Kymlicka 2015; Kymlicka and Banting 2006; Newton 2007).

The evidence on liberal's dilemma being reflected in welfare attitudes is indecisive. In a study of 17 European countries, Mau and Burkhardt (2009) found that ethnic diversity, and especially the proportion of non-Western foreigners has weak, yet statistically significant negative effect on support for redistribution and equal rights for migrants. In addition, Breznau and Eger (2016) and Eger and Breznau (2017) found that support for redistribution and public welfare provision was lower in European countries with higher shares of foreign-born population. In contrast, in a sample of 91 countries at different levels of economic development, Steele (2016) did not detect a negative correlation between ethnic diversity and support for redistributive social spending, though in countries with large inequalities an increase in the size of migrant groups was associated with less support for redistribution. Similarly, Senik et al. (2009) found no correlation between perceived extent of migration and support for redistribution in a sample of 22 European countries. Furthermore, Breznau and Eger (2016) could not replicate their finding on the country level that a higher share of migrants is linked with lower support for welfare provision on the regional level.

The second theoretical perspective, the concept of welfare chauvinism, also shares the notion that people are less willing to share resources with 'outsiders' compared to their 'in-group'. However, rather than undermining support for the welfare state as a whole (and especially for the universal and contributory entitlements), people are expected to oppose the extension of welfare rights to migrants (Cappelen and Peters 2018). ${ }^{1}$ With growing migration, it is argued, natives, especially those that rely heavily on the welfare state, increasingly fear that their share of the pie is being contested by a new group (see the 'group competition' theory, e.g., Blalock 1967; Coser 1956). In addition to migrants having a different identity, opposition to their obtaining social rights can also be explained by migrants scoring low on key deservingness criteria, such as reciprocity (they have contributed less in taxes than natives) and control (moving to another country is perceived to be a voluntary action, see van Oorschot 2006). Furthermore, the theory assumes that the higher the spending of the welfare state, the more the natives have to lose if increasing

\footnotetext{
1 A softer version of welfare chauvinism implies support for granting social rights to migrants only after they have met certain criteria, such as working and paying taxes or becoming citizens (Reeskens and van Oorschot 2012).
} 
migration leads to welfare retrenchment (see, critical of this argument, van Oorschot and Uunk 2007).

Unlike the liberal's dilemma, the existence of welfare chauvinism as such is not contested, presumably as opposition to migrants' social rights is more easily observable than change in attitudes towards the welfare state which may or may not be caused by opposition to migration. However, empirical evidence concerning the assumption that the scale of migration and the generosity of the welfare state increase welfare chauvinism is not unequivocal.

Regarding the effects of migration on welfare chauvinism, Gorodzeisky and Semyonov (2009) found in their analysis covering 21 European countries that support for restricting migration and opposition to equal rights for migrants was higher in countries with larger shares of non-European foreigners. In a time-series analysis of 17 European countries between 2002 and 2007, Meuleman et al. (2009) also found that higher inflow of migrants was associated with hardened attitudes towards migration. In contrast, the results from Cappelen and Peters' (2018) study of 21 European countries show that welfare chauvinism is lower in countries with higher levels of intra-EU migration, though it was also found that higher migration from Eastern European countries was associated with more welfare chauvinism. Likewise, Eger and Breznau's (2017) analysis suggests that a higher proportion of migrants reduces welfare chauvinism even though this also correlates with less support for public welfare provision and redistribution. Further, Van Der Waal et al. (2013) did not detect an effect of ethnic heterogeneity on welfare chauvinism in 10 European countries and Koning (2013) does not find a relationship between immigrant welfare dependency and welfare chauvinism.

In the case of the effects of social spending, the evidence appears more consistent, but is in contradiction to welfare chauvinism theory. Mewes and Mau (2013) found that in a sample of 26 European countries, higher social protection expenditure was associated with less welfare chauvinism. Similarly, in a study of 15 advanced welfare states Crepaz and Damron (2009) found that higher degree of decommodification and social spending was correlated with less welfare chauvinism. Furthermore, Reeskens and van Oorschot (2012) found that in 24 European countries higher social expenditure was associated with lower preference for excluding migrants completely from welfare provision.

Summing up the two main theoretical positions on preferences for the welfare state in the context of increasing migration, we argue that these positions are not necessarily competing theories explaining the same phenomenon. Instead, it is more fruitful to think of them as two distinctive types of negative reactions that people may have to the same phenomenon; for some, the whole concept of the welfare state is devalued because of migration (diminished solidarity), while others just want to continue business as usual by restricting migrants' access to welfare benefits (exclusive solidarity).

However, we claim that it would be erroneous to consider that migration can only undermine welfare solidarity in one way or another. Instead, we suggest that the two separate dimensions - national solidarity and openness to migration - can interact at the individual level in different ways. Thus, we complement the two types of attitudes on the interrelation of migration and welfare state with two other types equally 
likely to exist: 'extended solidarity' and 'cosmopolitan solidarity'. Such a taxonomy of four ideal types reflects the two-dimensional phenomenon more precisely and will thus render the analysis of the interrelation of attitudes towards migration and the welfare state more adequate. The two additional types are based on the following theoretical reflections:

First, research on egalitarianism has shown that egalitarians express strong support for the welfare state (Andreß and Heien 2001; Blekesaune and Quadagno 2003). At the same time, they are also shown to be open for migrants (Mau and Burkhardt 2009). Taking the two strands of research together, it follows that for people with an egalitarian worldview, both the welfare state and migration are remedies for social injustices. At the country level, more comprehensive welfare states can create a society showing more solidarity that includes migrants, for example because people feel less competition with migrants due to the guarantee of social security (van Oorschot and Uunk 2007). Similarly, in more diverse societies, negative stereotypes diminish due to increasing inter-group contact, leading to a more accommodating attitude towards migrants' social rights (Cappelen and Peters 2018; Mewes and Mau 2013). We therefore expect that a sizable share of people in European countries will simultaneously be in favour of a comprehensive welfare state and open to migration, thus resulting in an 'extended solidarity'.

Second, some people feel that it is the duty of the society to look after those members who experience hardship, thus taking a humanitarian stance (Feldman and Steenbergen 2001). People adopt humanitarian values even when suspicious of an all-penetrating state and redistribution of incomes. Since migrants often are considerably poorer than native-born citizens and they often flee appalling political, economic and social conditions in their countries, it is natural that they should attract empathy from people with humanitarian sentiments irrespective of the latter's ideas about the role of the state in the economy (Emmenegger and Klemmensen 2013). Further, economically well-off migrants, such as 'expats' working with international companies, will not create extra costs for the welfare state; quite the opposite, they will contribute to it. Thus, the belief in equality of opportunity and contempt for ethno-racial discrimination is characteristic not only for egalitarian people, but also for people who cherish meritocracy and individualism. Finally, Europeans are becoming increasingly aware of the demographic challenges arising from declining fertility rates and their possible repercussions, which is likely to make them more receptive to migration as a possible remedy, especially if they have an ideological viewpoint that combines humanitarianism with meritocracy and individualism. Thus, we anticipate that another group of people in European countries will hold positive views about migrants and their social rights even though they do not possess a particularly strong attachment to the welfare state, leading to a 'cosmopolitan solidarity'.

Following these arguments, we propose that there are four types of welfare solidarity in present European welfare states: cosmopolitan, diminished, exclusive and extended. The advantage of this theoretical framework over previous research based on regression analysis is that our approach does not concentrate on a single negative link between migration and welfare solidarity and therefore does not seek to average out the effects into a single parameter. Instead, it allows for multiple types of 
combinations of the two phenomena at individual level. This is important as a small, but well-organised group of people with diminished or exclusive solidarity can exert political pressure for welfare retrenchment or restriction of migrants' access to the welfare system even when on average a society is in favour of a strong welfare state and is open to migrants.

As far as we are aware, there is only one study which uses a similar non-linear approach for establishing the relation between attitudes towards migration and the welfare state. Kulin et al. (2016) applied Latent Class Analysis method to ESS4 data to classify respondents based on their attitudes towards: (a) redistribution of income between rich and poor; (b) allowing additional migration into their countries; and (c) social rights of migrants. They identified five groups-'pro-welfare, anti-migration', 'exclusive', 'pro-welfare, pro-migration', 'anti-welfare, anti-migration', and 'inclusive'.

While we share the idea of non-linear relation between welfare and migration attitudes, we believe that this study has a number of conceptual and methodological limitations, which we try to avoid in our own analysis. First, attitudes towards redistribution between rich and poor is not a very accurate proxy of attitudes towards the welfare state in general; as pointed out by Barr (2001), most of the redistribution that occurs in welfare states is horizontal, across life-cycle, rather than between income groups. Therefore, people's opinions about vertical redistribution cannot be treated as an indication of their general attitude towards a complex, multifaceted institution that also serves other critical functions such as the management of social risks and uncertainty. Second, using openness to additional migration and attitudes towards migrants' social rights as separate dimensions reflects an implicit assumption that the two are orthogonal-which is very unlikely to be the case. In our own analysis we found that general attitudes towards migrants and their social rights form a single latent factor. Third, Kulin and colleagues' results are very likely to be influenced by their choices of cut-off points made when dichotomising their categorical variables. Fourth, two groups identified by Kulin and colleagues_-inclusive' and 'prowelfare, pro-migration' - appear to be very similar in all respects with the exception that the latter want to grant social rights to migrants after they have contributed to the welfare system through paying taxes, while the former do not require such a conditionality. We believe that contribution requirement is not necessarily a sign of having reservations against migrants-access to most welfare benefits is conditional on previous contributions for native citizens as well. Thus, it seems appropriate to treat 'inclusive' and 'pro-welfare, pro-migration' groups as a single one, which would correspond to the extended solidarity group in our classification. We thus refine their previous exploratory insights with a theory-driven and methodologically more rigid approach.

\section{Research hypotheses}

To illustrate the practicality of our taxonomy our first task is to verify that each of the proposed ideal types is represented by a substantial number of persons both across the European continent and in individual countries. Second, we need to understand 
how the propensity of holding each type of solidarity is influenced by individualand country-level factors. Even though the theories presented above focus on the country-level, they also provide important clues regarding how various individual characteristics may render people more likely to hold one of the four solidarities.

Recalling that the liberal's dilemma is expected to materialise through ethnic diversity diminishing mutual trust among citizens and, as a consequence, less social trust leading to less solidarity, our first hypothesis is that lower social trust will be correlated with higher odds of having diminished solidarity (H1).

The welfare chauvinism theory, on the other hand, suggests that citizens and especially those born in the country want to exclude migrants from benefits. Also, the group competition theory assumes that persons threatened by migrants, i.e. those who benefit from social security and those less well-off are more likely to adopt the values of exclusive solidarity. Hence, our second hypothesis is that compared to people with opposite characteristics, citizens, natives, unemployed and those who expect to be unemployed soon, financially insecure people and those whose primary source of income is social transfers will be more likely to hold an exclusive solidarity compared to other solidarity types (H2).

In line with enlightenment theory (Robinson and Bell 1995), our expectation is that people with higher education are more likely to hold universalist values, which should render them more likely to show an extended solidarity rather than other types of solidarity $(\mathrm{H} 3)$.

Finally, we assume that individualistic, meritocratic and cosmopolitan values are more widespread in big cities than elsewhere. Therefore, our fourth hypothesis is that urban people will be more likely to express a cosmopolitan solidarity than other solidarity types compared to people residing in other locations (H4).

Turning to country-level factors, our fifth hypothesis with the goal of testing the liberal's dilemma theory is that a higher stock of migrants (or refugees) will be correlated with a higher probability of having diminished solidarity compared to other solidarity types (H5).

Similarly, with the sixth hypothesis we test the welfare chauvinism theory and its assumptions regarding migration flow, expecting that a higher inflow of migrants will be associated with a higher propensity of having exclusive solidarity compared to other types (H6).

Further, still on the welfare chauvinism theory but now testing its assumptions regarding welfare spending, our final hypothesis states that higher social protection spending will be correlated with a higher probability of expressing exclusive solidarity compared to other solidarity types (H7).

\section{Methodology}

\section{Data}

This paper utilizes the data of the eighth round of the European Social Survey (ESS) conducted in 2016. The ESS is an academically driven cross-sectional survey that collects data on attitudes, beliefs, and behavioural patterns through face-to-face 


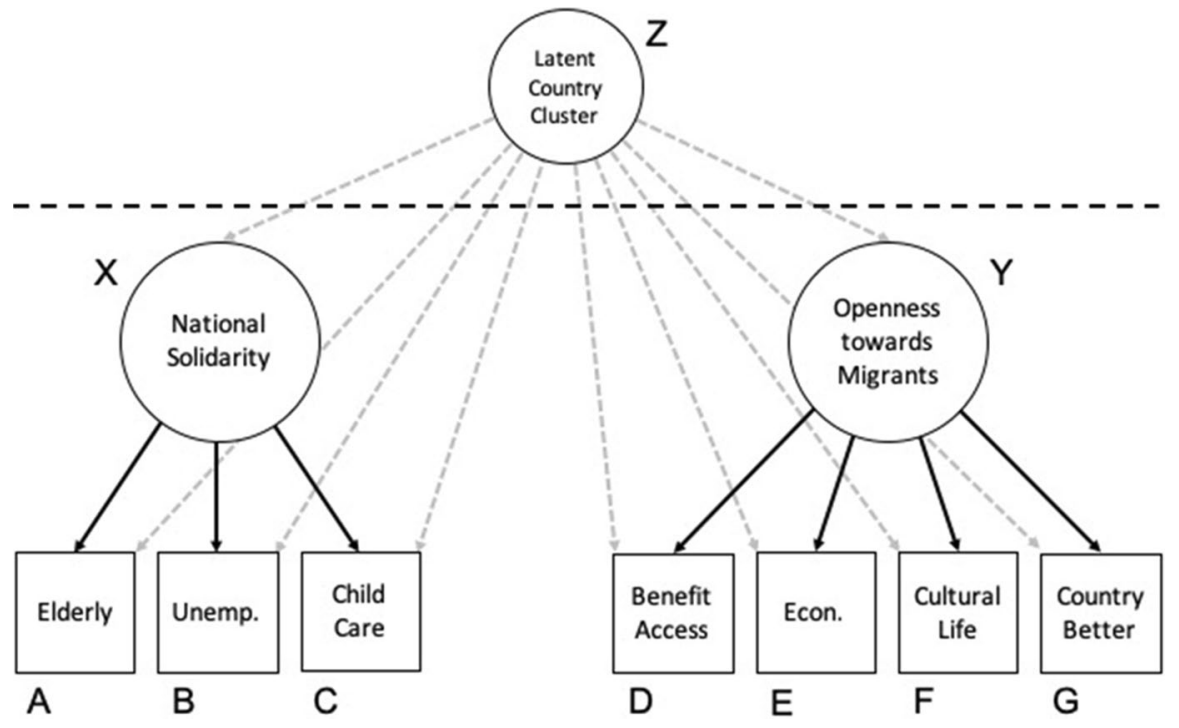

Fig. 1 Conceptual model

interviews every two years. The eighth wave of the ESS was fielded in 23 countries (Austria, Belgium, Czech Republic, Estonia, Finland, France, Germany, Hungary, Iceland, Ireland, Israel, Italy, Lithuania, the Netherlands, Norway, Poland, Portugal, Russian Federation, Slovenia, Spain, Sweden, Switzerland, United Kingdom) and offers nationally representative samples of at least 1250 respondents per country. ${ }^{2}$ The eighth wave contains a rotating module on welfare attitudes with multiple questions about various aspects of the welfare state, while also including a set of items concerning attitudes towards migrants. These unique features make the ESS8 a dataset of choice for the purpose of our research. In all analyses, we use design survey weights supplied by the ESS.

\section{Dependent variables}

While it is now commonly acknowledged that attitudes towards the welfare state are multidimensional (Roosma et al. 2012), it has been argued that the dimension that comes closest to measuring the underlying concept of 'welfarism' is preferences for the range of government responsibilities for different types of welfare transfers and services (van Oorschot and Meuleman 2012). Accordingly, our first latent variable-preference for welfare provision (i.e. national solidarity)—is measured using three observed variables $(A-C)$ concerning people's preference for the role of the government in welfare provision. The question reads (letters in square brackets

\footnotetext{
2 The only exception is Iceland, where the sample size of 880 reflects its small size of population. For more detailed information about the ESS see: https://www.europeansocialsurvey.org/.
} 
indicate the variable's position in Fig. 1): "People have different views on what the responsibilities of governments should or should not be. For each of the tasks I read out please tell me on a score of 0-10 how much responsibility you think governments should have. 0 means it should not be governments' responsibility at all and 10 means it should be entirely governments' responsibility. Firstly to ...

- $[\mathrm{A}]$...ensure a reasonable standard of living for the old?"

- [B] ...ensure a reasonable standard of living for the unemployed?"

- $[\mathrm{C}]$...ensure sufficient childcare services for working parents?"

The second latent variable-openness to migrants-is measured using four observed variables:

- [D] "When do you think they [people coming from other countries] should obtain the same rights to social benefits and services as citizens already living here?"

- [E] "Is it generally bad or good for [country]'s economy that people come to live here from other countries?"

- $[\mathrm{F}]$ "Is [country]'s cultural life generally undermined or enriched by people coming to live here from other countries?"

- $[\mathrm{G}]$ "Is [country] made a worse or a better place to live by people coming to live here from other countries?"

The fourth variable $(D)$ is measured by five response categories (in order of increasing support): (1) they should never get the same rights; (2) once they have become a citizen; (3) only after they have worked and paid taxes for at least a year; (4) after living in a country for a year, whether or not they have worked and paid taxes; (5) immediately on arrival. The last three variables $(E-G)$ are measured on a scale from 0 to 10 , with 0 indicating the most negative attitude and 10 the most positive.

\section{Independent variables: individual level}

In the analysis, we use the following individual-level variables. Trust in people is measured through a question which asks respondents whether "Most people can be trusted or you can't be too careful in dealing with people". Responses are measured on a 10-point scale with higher values implying higher trust. Being born in the country and being citizen are binary variables. Respondent's employment status categories are: paid work; in education; unemployed; economically inactive; permanently sick or disabled; retired; housework, looking after children; and other. Answer categories for perceived likelihood of unemployment in the coming 12 months are: not at all likely; not very likely; likely; very likely; never worked or no longer working. Feeling about household income has four categories: living comfortably on present income; coping on present income; difficult on present income; and very difficult on present income. Main sources of household income are: wages, other market income and informal transfers; social transfers; and other. Education status comprises of three categories: lower secondary; upper secondary; tertiary. Place of residence 
differentiates between: a big city; the suburbs or outskirts of a big city; a town or a small city; a country village; a farm or home in the countryside. We also control for age (in years) and gender.

\section{Independent variables: country level}

To capture the different dimensions of migration, we use three indicators in the analysis: The stock of refugees is the number of refugees divided by the total population. The stock of migrants is the share of people in country who have been born in another country. The flow of migrants is measured through net annual migration which is the difference between immigrants and emigrants divided by the total population. All three indicators were obtained from World Bank's Open Data source (httpss://data.worldbank.org). Social protection spending is measured as a share of GDP and was obtained from IMF Government Finance Statistics (https://data.imf. org/?sk=a0867067-d23c-4ebc-ad23-d3b015045405).

\section{Analytical strategy}

In order to answer our research questions and test the proposed hypotheses about welfare solidarity in Europe, we make use of Latent Class Factor Analysis (LCFA; see Magidson and Vermunt 2001). LCFA is a specific type of an often-used Latent Class Cluster Analysis (LCCA), but instead of categorical observed indicators, it uses continuous indicators to estimate the latent clusters. In that sense, it is closer to factor analysis as we formulate a model with two mutually independent dichotomous latent factors. This fits well our theorised dimensions of national solidarity and openness towards migrants, which are modelled as restricted LCFA with two independent dichotomous latent factors. LCFA is used as a descriptive instrument that operationalises and empirically describes the dispersion of people over the theorised taxonomy. We prefer this method over arbitrarily dichotomising scales derived from observed variables according to their averages or other clustering techniques because it allows us to stay as close as possible to the original data and to use a model-based approach which is parsimonious and easy to interpret. Unlike exploratory LCCA, our estimated LCFA approach models the two latent factors separately and assigns a position for each individual on each factor.

Accordingly, in Fig. 1, national solidarity and openness towards migrants are formulated as two independent latent factors, each measured by a set of observed items.

As we are dealing with a sample of observations nested within countries, we use the multilevel extension of latent class model proposed by Vermunt (2003, 2008). We apply a non-parametric multilevel latent class model that is similar to randomcoefficients logistic regression model (Agresti et al. 2000), with the difference that the dependent variable is not directly observed but latent. In comparison to the conventional approach of multilevel modelling with random effects, we do not assume any particular parametric distribution of the random components (Finch and French 2014) and hence pose less restrictive assumptions on the model (Vermunt and van Dijk 2001). Under the assumption that there exists a finite number of subgroups 
with different coefficients, the model creates categorical latent country clusters that can be used to account for fixed country-level characteristics similar to using country dummies (see Vermunt and van Dijk 2001; Rights and Sterba 2016). However, unlike using country dummies that would be perfectly collinear with any countrylevel predictor, our approach allows adding country-level predictors to the model. This is because countries are clustered in a lower number of groups that break the perfect collinearity and allow estimation of country-level effects.

The number of modelled latent country clusters is evaluated based on model fit indices. Our strategy for estimating the multilevel model is to sequentially increase the number of latent country clusters and evaluate the model fit. Conventionally, several model fit criteria are used with latent class models: the likelihood ratio $L^{2}$, Pearson $\chi^{2}$, or various information criteria (IC) indices. The former two have important limitations (see Hagenaars and McCutcheon 2002); especially with large datasets, absolute model fit criteria will almost always produce a significant result, which is not very informative. Moreover, model comparison significance tests are problematic in their own right, as the likelihood ratio statistic between two models is not chi-squared distributed (McLachlan and Peel 2000). Despite mentioned shortcomings, for transparency reasons, we report the log-likelihood (LL). As a second indicator for absolute model fit, we report estimated classification errors (to assess separation of the classes) for all models. For model selection, however, we rely on relative model fit indices, BIC and SABIC, which were shown to have more reliable properties for model selection (see simulation study by Nylund et al. 2007), especially if absolute fit can be considered strong for all solutions. The lower the BIC and SABIC, the better the model fit to the observed data.

The model has seven observed variables ( $A$ through $G$, shown as letters in Fig. 1), two latent variables ( $X$ and $Y$ ), and one grouping variable $(Z)$. Categories of observed variables are denoted as $i, j, k, l, m, n, o$ and unobserved variables as $t, u, v$, respectively. The final log-linear representation of the model is

$$
\begin{aligned}
\ln \left(F_{i j k l m n o t u v}\right)= & \lambda+\lambda_{i}^{A}+\lambda_{j}^{B}+\lambda_{k}^{C}+\lambda_{l}^{D}+\lambda_{m}^{E}+\lambda_{n}^{F}+\lambda_{o}^{G}+\lambda_{i t}^{A X}+\lambda_{j t}^{B X}+\lambda_{k t}^{C X}+\lambda_{l u}^{D Y}+\lambda_{m u}^{E Y} \\
& +\lambda_{n u}^{F Y}+\lambda_{o u}^{G Y}+\lambda_{i v}^{A Z}+\lambda_{j v}^{B Z}+\lambda_{k v}^{C Z}+\lambda_{l v}^{D Z}+\lambda_{m v}^{E Z}+\lambda_{n v}^{F Z}+\lambda_{o v}^{G Z}+\lambda_{t v}^{X Z}+\lambda_{u v}^{Y Z}
\end{aligned}
$$

where $\lambda_{i}^{A}$ is akin to intercept probability of $A$, and $\lambda_{i t}^{A X}$ to factor loading (the direct effect) between the observed variable $A$ and latent variable $X$. Finally, $\lambda_{i v}^{A Z}$ denotes the difference in intercept probability of variable $A$ by latent country cluster $Z$ and $\lambda_{t v}^{X Z}$ shows the difference in sizes of estimated classes of latent variable $X$ due to membership in a latent country cluster $Z$. For more about interpretation and log-linear representation of latent class models, see Hagenaars and McCutcheon (2002). To assess the effect of covariates on the probability of belonging to the four modelled latent clusters, we use a three-step approach (see Bakk et al. 2013).

Once we reach the best model fit with regard to controlling for fixed country-level characteristics, we proceed with conducting sensitivity analysis to our assumptions about measurement equivalence across countries. Our model assumes that concepts of national solidarity and openness towards migrants are partially homogenous across the investigated countries (see Kankaraš et al. 2010). Specifically, we assume that the relationship between the latent variables $(X, Y)$ and observed variables 
$(A-G)$ do not differ by the latent country classes $(Z)$. We test this by first releasing the model assumption about independence between observed indicators $(A-G), X$, and $Z$, by sequentially adding interaction terms $\lambda_{i t v}^{A X Z}, \ldots, \lambda_{\text {ouv }}^{G Y Z}$. Subsequently, we try out whether we could reach a more parsimonious model by constraining intercepts of observed variables $(A-G)$ to be independent of the latent country class by constraining $\lambda_{i v}^{A Z}, \ldots, \lambda_{o v}^{G Z}$ to be equal to 0 (this would be considered moving towards structural homogeneity-higher level of measurement equivalence). Evaluating the model fit will show whether we truly found the best fitting model and whether our results are dependent on our assumptions about measurement equivalence.

\section{Results}

The results section proceeds as follows: first, we present model fit criteria and explain the logic behind selecting our final model. Then we show the distribution of national solidarity and openness towards migrants within the extracted latent classes. Next, we present the results on the individual-level, i.e. the association of latent groups with socio-economic and demographic variables. In the last part, we test the two theories postulating a relationship between country-level migration and social spending and the propensity of holding one of the four solidarity types.

\section{Model selection}

Following our theoretical discussion, we estimate a model with two independent factors that results into four theoretically deduced clusters. In terms of model fit, the estimated two-factor model is a substantial improvement to the one-factor model; however also adding the third and fourth factors provide marginal improvements to model fit compared to models with a lower number of factors. This is expected, as adding factors will usually result in better model fit because models with more factors have fewer restrictions. Nevertheless, adding more factors does not necessarily contribute to our understanding of the model. In case of three- and four-factor models, the added clusters are very low in size and are usually refinements of larger substantial theoretically based classes. We therefore decide to analyse the model with two factors which produces clusters of substantial size $(>5 \%)$ and remains theoretically grounded.

In the first part of Table 1 (1. Country Cluster), we iteratively increase the number of latent country clusters to account for fixed country-level characteristics. As can be seen, Model 4 with four country clusters has the best model fit.

We test our model assumption about measurement equivalence across the countries in the second (2. Release model assumptions) and third (3. Constrain model assumptions) parts of Table 1. We compare these tests to the best model we obtained so far (Model 4) and see that neither of these manipulations show a better model fit in terms of BIC and SABIC. We therefore conclude that neither of these manipulations yield evidence for a different level of measurement equivalence and proceed to the analysis with a partially homogenous model. These tests also provide important 


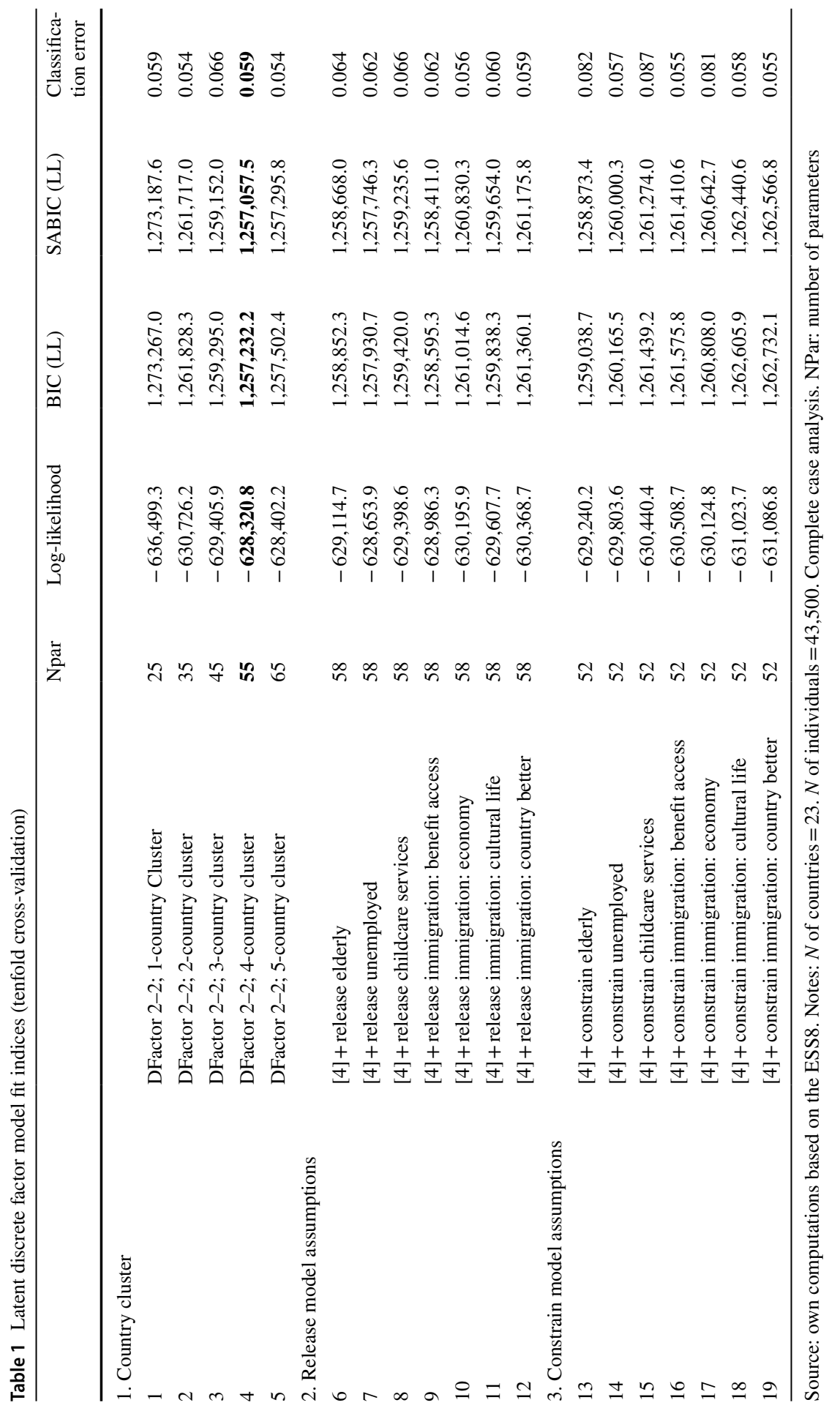

称 
Table 2 Latent group profiles: Estimated means (and standard errors) per indicator

\begin{tabular}{|c|c|c|c|c|}
\hline & $\begin{array}{l}\text { High national, } \\
\text { high openness } \\
\text { 'Extended } \\
\text { Solidarity' }\end{array}$ & $\begin{array}{l}\text { High national, } \\
\text { low openness } \\
\text { 'Exclusive } \\
\text { Solidarity' }\end{array}$ & $\begin{array}{l}\text { Low national, } \\
\text { high openness } \\
\text { 'Cosmopolitan } \\
\text { Solidarity' }\end{array}$ & $\begin{array}{l}\text { Low national, low } \\
\text { openness 'Diminished } \\
\text { solidarity' }\end{array}$ \\
\hline & (1) & (2) & (3) & (4) \\
\hline Latent group size & $56 \%$ & $28 \%$ & $11 \%$ & $5 \%$ \\
\hline \multicolumn{5}{|l|}{ National solidarity } \\
\hline Elderly & $\begin{array}{l}9.67 \\
(0.11)\end{array}$ & $\begin{array}{l}9.72 \\
(0.10)\end{array}$ & $\begin{array}{l}6.30 \\
(0.31)\end{array}$ & $\begin{array}{l}6.35 \\
(0.30)\end{array}$ \\
\hline Unemployed & $\begin{array}{l}8.09 \\
(0.14)\end{array}$ & $\begin{array}{l}8.12 \\
(0.15)\end{array}$ & $\begin{array}{l}5.68 \\
(0.17)\end{array}$ & $\begin{array}{l}5.70 \\
(0.17)\end{array}$ \\
\hline $\begin{array}{l}\text { Childcare for working } \\
\text { parents }\end{array}$ & $\begin{array}{l}9.10 \\
(0.17)\end{array}$ & $\begin{array}{l}9.17 \\
(0.16)\end{array}$ & $\begin{array}{l}6.92 \\
(0.25)\end{array}$ & $\begin{array}{l}6.98 \\
(0.25)\end{array}$ \\
\hline \multicolumn{5}{|l|}{$\begin{array}{l}\text { Openness towards } \\
\text { migrants }\end{array}$} \\
\hline Immigrants: economy & $\begin{array}{l}7.27 \\
(0.15)\end{array}$ & $\begin{array}{l}3.74 \\
(0.21)\end{array}$ & $\begin{array}{l}7.12 \\
(0.20)\end{array}$ & $\begin{array}{l}3.57 \\
(0.25)\end{array}$ \\
\hline Immigrants: cultural life & $\begin{array}{l}7.72 \\
(0.18)\end{array}$ & $\begin{array}{l}3.99 \\
(0.24)\end{array}$ & $\begin{array}{l}7.53 \\
(0.22)\end{array}$ & $\begin{array}{l}3.78 \\
(0.27)\end{array}$ \\
\hline Immigrants: country better & $\begin{array}{l}7.17 \\
(0.19)\end{array}$ & $\begin{array}{l}3.75 \\
(0.24)\end{array}$ & $\begin{array}{l}6.99 \\
(0.22)\end{array}$ & $\begin{array}{l}3.56 \\
(0.26)\end{array}$ \\
\hline Immigrants: benefit access & $\begin{array}{l}3.06 \\
(0.06)\end{array}$ & $\begin{array}{l}2.38 \\
(0.06)\end{array}$ & $\begin{array}{l}3.00 \\
(0.07)\end{array}$ & $\begin{array}{l}2.33 \\
(0.08)\end{array}$ \\
\hline
\end{tabular}

Source Own computations based on the ESS8. Notes: $N$ of countries $=23 . \quad N$ of individuals $=43,500$. Complete case analysis

evidence for comparability of our extracted segments. Partial homogeneity means that although intercepts for indicators are different for each country, the loading (i.e. the connection) between the observed indicators and the latent factors are equal, hence the meaning of the factors can be considered equivalent across investigated countries.

\section{National solidarity and openness towards migration}

We continue the analysis by inspecting the sizes of the four latent groups that resulted from our LCFA analysis and whether they are clearly distinguishable in terms of the observed variables of the two dimensions (Table 2). The largest group comprises over half of all respondents (56\%). These people appear to hold an extended solidarity as they exhibit very high preferences for public provision of childcare and high support for the elderly and the unemployed. At the same time, they share a positive view of economic, cultural and social benefits of migration. They are also most in favour of extending the welfare provision to foreigners. The second group comprises over a quarter of the sample (28\%). People in this group express even slightly higher support for welfare provision for fellow citizens but have rather negative opinions 
about migration and are less in favour of granting social rights to migrants. Thus, we identify this group as the exclusive solidarity type. Slightly more than a tenth of respondents (11\%) appear in the third group, which is much more reserved about the government's role in welfare provision, but similarly to the first group, has positive attitudes towards migrants and their social rights. Therefore, this group puts forward a cosmopolitan solidarity. The fourth group represents a clear minority (5\%). It includes people with limited support for public welfare, negative attitudes towards migration and more clearly expressed opposition to foreigners' social rights. Therefore, we identify them as the diminished solidarity type. It should be noted that the sizes of the groups identified by us differ considerably from those in Kulin and colleagues' (2016) analysis. For example, they found that 'anti-welfare, anti-migration' cluster which comes close to our diminished solidarity group comprised $14 \%$ of the sample. Also, their 'pro-welfare, pro-immigration' (22\%) and 'inclusive' (11\%) clusters are considerably smaller than our extended solidarity cluster that would combine the two. However, given the considerable conceptual and methodological differences discussed earlier, as well as differences in time period and samples between the two studies, such differences do not seem to be surprising.

We thus find empirical support for our suggestion that the liberal's dilemma and welfare chauvinism theories are neither mutually exclusive, nor do the theories cover the relationship between migration and support for the welfare state adequately. We rather find support for the two-dimensional structure including national solidarity and openness towards migrants leading to four ideal types of solidarity. We furthermore remark that all groups support the welfare state. ${ }^{3}$ Even in the group where preferences for public provision are lower, namely the cosmopolitans, support for each policy area is on average above the midpoint of the scale. Thus, we conclude that the support for general welfare provision by the state is anchored widely within European countries. However, there are differences in perceptions of how far the state should go in providing social benefits.

\section{Individual-level relationships}

Table 3 presents the results of the multinomial multilevel logistic model fitted to test our hypotheses regarding the relation between individual-level predictors and the propensity to hold one of the four types of solidarity. The reference category is diminished solidarity. In line with our first hypothesis which reflects the logic of the liberal's dilemma we find that lower social trust is correlated with having a higher propensity of having diminished solidarity compared to extensive and cosmopolitan solidarities. In relation to the second hypothesis regarding exclusive solidarity the

\footnotetext{
3 Additional tests indicate that the findings for national solidarity hold as well for transnational solidarity. Most respondents are in favour of a hypothetical transnational welfare system for the poor, measured by a question whether people are against or in favour of an EU-wide social benefit scheme for all poor people. However, there are important differences in the extent of rejection of such a system: $29 \%$ of people with extended solidarity are against, vs. $36 \%$ of those holding an exclusive solidarity, $39 \%$ of those holding a cosmopolitan solidarity and $48 \%$ of those with a diminished solidarity.
} 


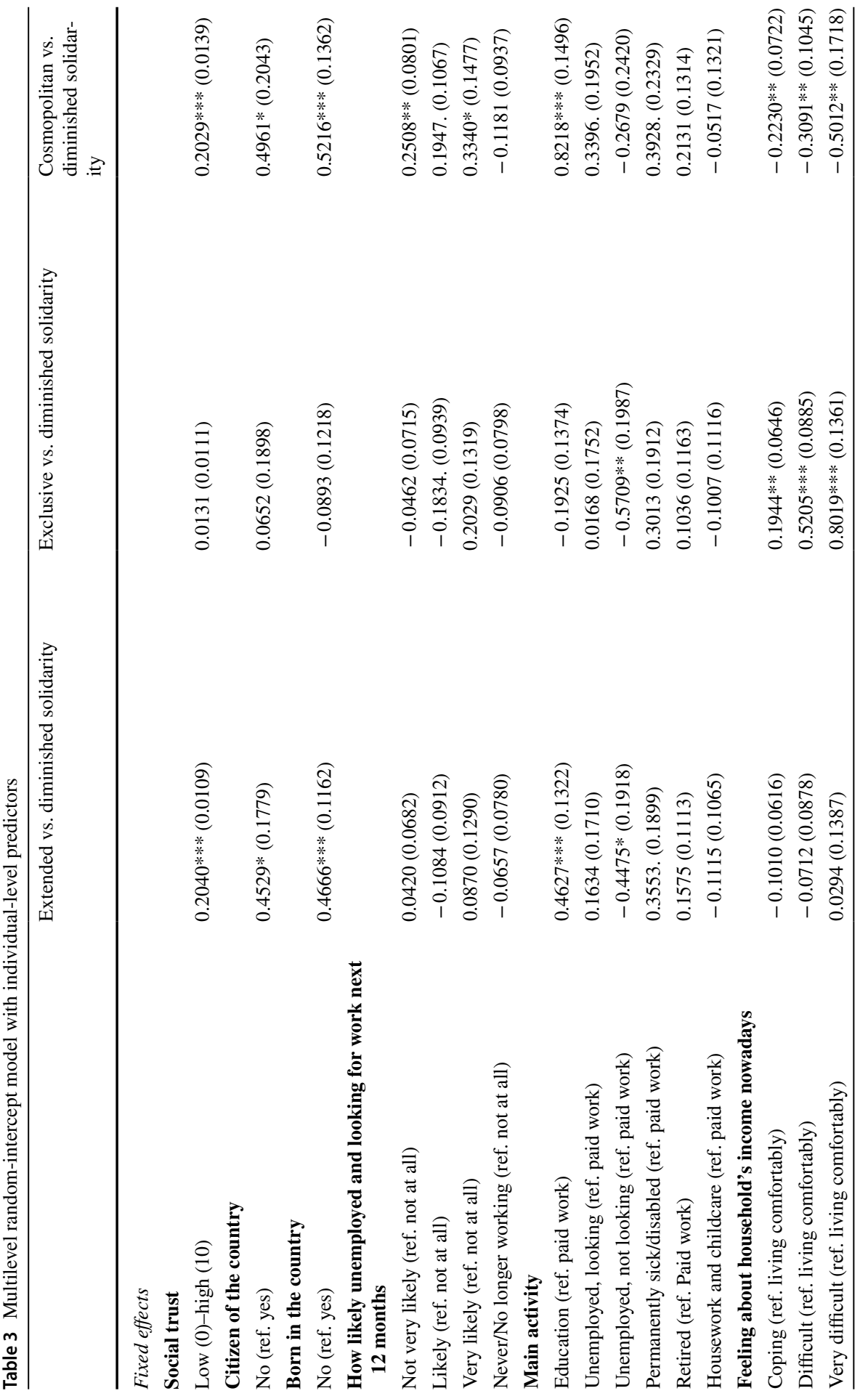




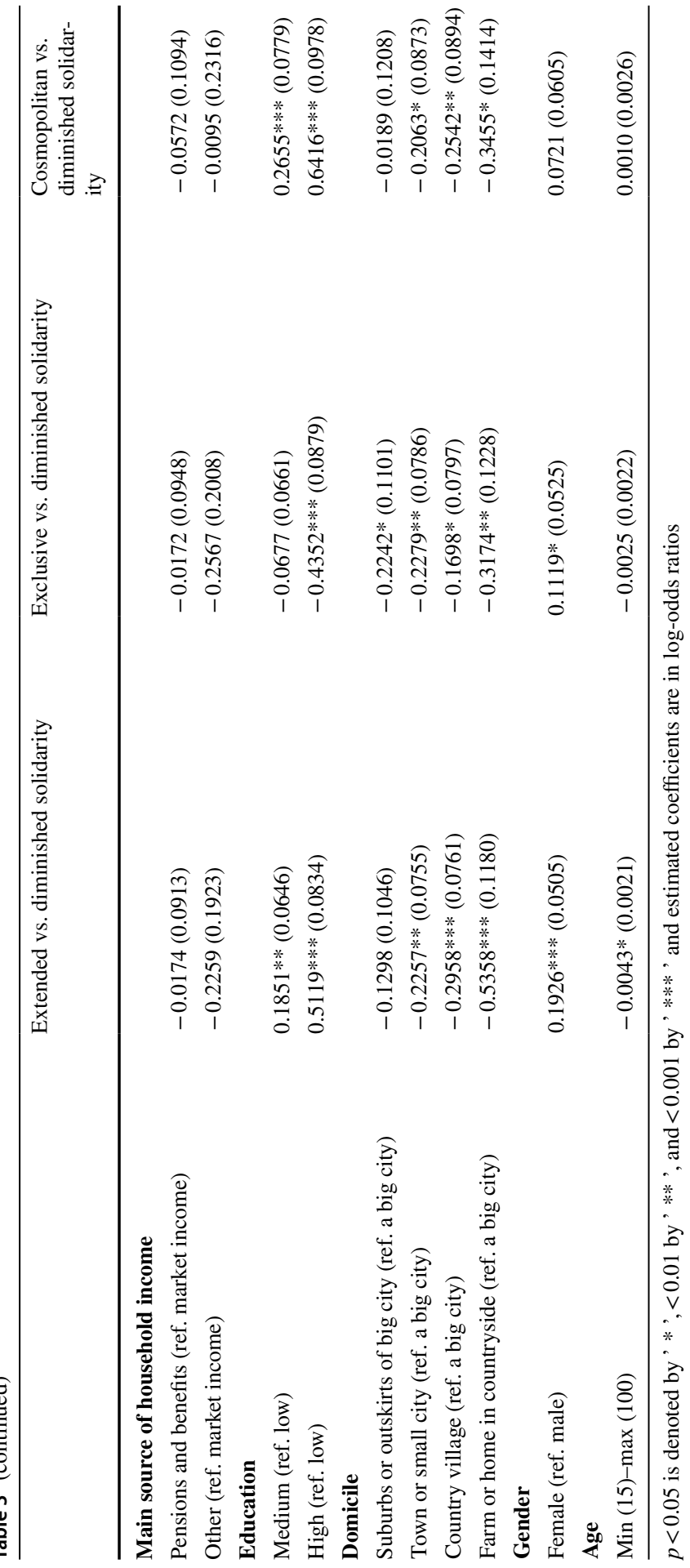

起。 


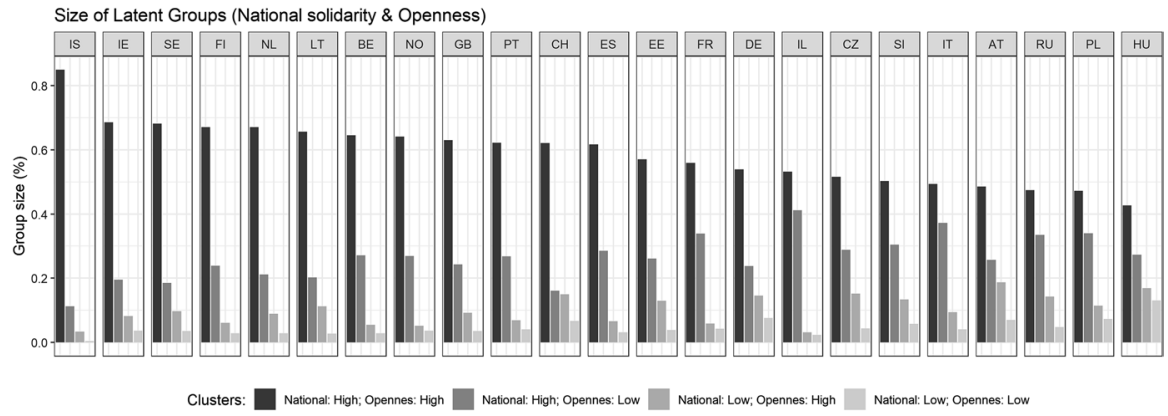

Fig. 2 Size of latent groups by countries. Source: own computations based on the ESS8. Notes: $N$ of countries $=23 . N$ of individuals $=43,500$. Complete case analysis

evidence is more mixed. While we find that, as postulated in $\mathrm{H} 2$, the more difficult people find it to live on their present income, the more likely they are to express exclusive solidarity than other solidarity types, it is less clear regarding natives and citizens, who are more likely to have not only exclusive but also diminished solidarity than an extended or cosmopolitan one. In addition, compared to people in paid work, the discouraged unemployed (i.e. those who are unemployed but do not look for job) are more likely to have diminished rather than exclusive solidarity. Even contrary to our expectation, there is no association between the main source of income and the propensity of having any of the four types of solidarities. The perceived risk of being unemployed in the near future is also not correlated with higher likelihood of belonging to one of the types, the minor exception being that people with not very likely or very likely risk of future unemployment are more inclined to have cosmopolitan solidarity as opposed to diminished solidarity. To sum up, we find partial confirmation of our Hypothesis 2: Some, but not all variables indicating people having something to lose given migration are linked to exclusive solidarity; financial insecurity and being a citizen or a native are more likely to lead to exclusive solidarity while the main source of income and risk of unemployment is not related to a higher propensity of exclusive solidarity.

With regard to the third hypothesis about the enlightening effects of education, we find that the higher the level of achieved education, the more likely people are to hold extended solidarity compared to exclusive or diminished ones. However, a higher level of education has an even slightly stronger link to having the cosmopolitan solidarity. Similarly, in relation to the fourth hypothesis, as predicted, compared to people living in other locations, people living in more urban areas appear more likely to have cosmopolitan solidarity than diminished solidarity. However, compared to other groups, urban residents also exhibit a higher likelihood of having extended and exclusive solidarities (as opposed to diminished solidarity) as well.

\section{Country-level relationships}

Before inspecting the correlations between the extent of migration, welfare spending and propensity for holding a specific type of solidarity, it is instructive to consider 
Table 4 Multilevel random-intercept model with country-level predictors

Extended vs. dimin- Exclusive vs. dimin- Cosmopolitan ished solidarity ished solidarity vs. diminished solidarity

\begin{tabular}{llll} 
Fixed effects & & & \\
Refugees, \% of population & $-0.0905(0.2839)$ & $-0.2121(0.2540)$ & $0.0906(0.1640)$ \\
Stock of migrants, \% of population & $0.0122(0.0253)$ & $0.0290(0.0225)$ & $-0.0305^{*}(0.0144)$ \\
Net migration flow, \% of population & $-0.1172(0.0806)$ & $-0.0950(0.0719)$ & $-0.0070(0.0458)$ \\
Social spending, \% GDP & $-0.0112(0.0318)$ & $0.0209(0.0285)$ & $-0.0363^{*}(0.0185)$ \\
Intercept & $1.6863^{*}(0.6649)$ & $1.4552^{*}(0.6000)$ & $0.2248(0.4144)$ \\
Random effects & & & \\
Residual $\left(\pi^{2} / 3\right)$ & 3.29 & 3.29 & 3.29 \\
Intercept $\left(\sigma^{2}\right)$ & 0.273 & 0.212 & 0.069 \\
\hline
\end{tabular}

$p$ value $<0.05$ is denoted by ${ }^{*}$, and estimated coefficients are in log-odds ratios. Individual-level predictors are controlled for but not reported

the similarities and differences in the prevalence of the solidarity types across countries. It is notable that the propensity for solidarity-types exhibits the same ordinal structure (i.e. Extended $>$ Exclusive $>$ Cosmopolitan $>$ Diminished) in all of the countries as Fig. 2 shows). However, the differences are indeed still substantial and they follow a certain geographical pattern. At one extreme, there are Nordic and Western European countries-Iceland, Ireland, Sweden, Finland and the Netherlands, together with Lithuania-where extended solidarity forms an overwhelming majority. In these countries, more than $65 \%$ of people believe in the need for a strong involvement of the government in welfare provision and see various benefits of migration. Iceland is particularly noteworthy because $85 \%$ of respondents belong to this category, which is 16 percentage points higher than in Ireland, the country with the second highest incidence of extended solidarity. The exclusive solidarity constitutes the second largest group in countries with the highest share of extended solidarity, but their share does not exceed $25 \%$. The other two groups represent a tiny proportion in these countries and diminished solidarity is practically non-existent in Iceland.

At the other extreme of Fig. 2, we find three Eastern European countries-Hungary, Poland and Russia followed by Austria and Italy. In these countries, less than half of the population belongs to the extended solidarity type. The exclusive solidarity is more prevalent in Israel (41\%), Italy (37\%), Poland (34\%), France (34\%) and Russia (33\%). The cosmopolitans are mostly represented in Austria (19\%), Hungary (17\%), Czech Republic (15\%), Switzerland (15\%) and Germany (15\%), while the diminished solidarity exceeds $10 \%$ only in Hungary.

Table 4 displays the results of the multilevel multinomial model fitted to test the hypotheses postulating a relationship on the country-level between the prevalence of a certain type of solidarity and migration and welfare spending. To control for composition effects, in this model, individual predictors used in the previous model are controlled for, but not reported as the coefficients are very similar to those discussed 
above. With regards to the fifth hypothesis, we find that the stock of refugees has no statistically significant effect, while a larger stock of migrants is associated with a higher propensity of having diminished solidarity as compared to cosmopolitan solidarity, but not compared to extended or exclusive solidarity. Thus, the hypothesis that migration increases the likelihood of diminished solidarity compared to all other solidarity types, as proposed by the liberal's dilemma theory, is not borne out by our evidence.

We also fail to find support for the sixth hypothesis: higher inflow of migrants has no statistically significant effect on the propensity of holding any type of solidarity. As for the final hypothesis, a higher social protection spending is associated with a lower propensity of holding cosmopolitan solidarity compared to diminished solidarity, whereas the welfare chauvinism theory suggests that higher welfare spending will be correlated with higher propensity of having exclusive solidarity compared to other types. Therefore, we reject this hypothesis as well. In sum, we find no effect of the theoretically relevant contextual variables postulated by the liberal's dilemma and the welfare chauvinism theories, which provides further evidence for questioning the explanatory power of these theories. Rather, the findings suggest that the multidimensional conceptualisation of attitudes towards migration and welfare seems to be useful for the analysis of how migration might affect solidarity within and across countries.

\section{Conclusion}

Informed by the liberal's dilemma and the welfare chauvinism theories, welfare attitudes literature has traditionally viewed migration as a potential hazard to welfare solidarity, and by extension, to the future of European welfare states. In this paper, we have argued that such an unidimensional approach to establishing the link between attitudes towards migration and the welfare state is not sufficient to capture the interaction of these two complex phenomena at the individual level. As an alternative, we have offered a taxonomy of four different types of solidarity based on people's preferences for public welfare provision and their openness to migrants and their social rights. To illustrate the practical usefulness of this taxonomy, we have applied LCFA to European Social Survey data.

The results indicate that extended solidarity (strong support for both migration and the welfare state) is most widespread as it accounts for $56 \%$ of the sample. Furthermore, support for the welfare state is above the midpoint in all other groups as well, demonstrating its enduring popularity. However, it should also be stressed that the share of people with exclusive solidarity is also high across the sample (28\%) and that in several countries people with extensive solidarity are a minority despite being more numerous than people with other types of solidarity. Hence, the European social-democrats' quest to simultaneously promote both welfare and migrants' rights is certainly not an easy task, but at least according to public opinion data they do not have to fear that their electoral setback will lead to a major retrenchment of European welfare states. 
Our results are in sharp contrast with the results of Kulin et al. (2016), even as our analysis covers a later point in time and a somewhat different sample. They conclude that "for most Europeans, supporting both immigration and welfare is unlikely" (p. 1), while we find that more than 50\% of Europeans actually do support both. This difference is due to several conceptual and methodological shortcomings in Kulin and colleagues' analysis, especially with regards to the operationalisation of key concepts, dichotomisation of variables and arbitrary selection of the cut-off points. Our study thus shows that addressing these issues leads to a strikingly different interpretation that seems much more plausible to us.

Our findings also shed light on key individual characteristics that make people more or less likely to belong to one of the four solidarity groups. As expected, urban, financially secure, highly educated people and people with higher trust in fellow citizens are less likely to have diminished or exclusive solidarity. However, these characteristics have very similar effects on the propensity of holding either extended or cosmopolitan solidarity and further research is needed to identify the factors that contribute to people holding one of these solidarities as opposed to another. Similarly, while our results suggest that the extent of migration and welfare spending are not related to the propensity of holding solidarity types as predicted by the liberal's dilemma and the welfare chauvinism theories, more definitive conclusions require additional research with larger country samples and preferably longitudinal designs.

Funding Open Access funding provided by University of Neuchâtel. This research has been funded through the ERA.Net RUS Plus Project "Public Attitudes to Welfare, Climate Change and Energy in the EU and Russia (PAWCER)". Dimitri Gugushvili received additional funding through the Flemish Research Council (FWO) Grant \#IRI I001519N.

\section{Compliance with ethical standards}

Conflict of interest On behalf of all authors, the corresponding author states that there is no conflict of interest.

Open Access This article is licensed under a Creative Commons Attribution 4.0 International License, which permits use, sharing, adaptation, distribution and reproduction in any medium or format, as long as you give appropriate credit to the original author(s) and the source, provide a link to the Creative Commons licence, and indicate if changes were made. The images or other third party material in this article are included in the article's Creative Commons licence, unless indicated otherwise in a credit line to the material. If material is not included in the article's Creative Commons licence and your intended use is not permitted by statutory regulation or exceeds the permitted use, you will need to obtain permission directly from the copyright holder. To view a copy of this licence, visit http://creativecommons.org/licen ses/by/4.0/.

\section{References}

Agresti, A., J.G. Booth, J.P. Hobert, and B. Caffo. 2000. Random-effects modelling of categorical response data. Sociological Methodology 30 (1): 27-80.

Alesina, A., and E. Glaeser. 2004. Fighting poverty in the US and Europe: A world of difference. Oxford: Oxford University Press. 
Andreß, H.-J., and T. Heien. 2001. Four worlds of welfare state attitudes? A comparison of Germany, Norway, and the United States. European Sociological Review 17 (4): 337-356.

Bakk, Z., F.B. Tekle, and J.K. Vermunt. 2013. Estimating the association between latent class membership and external variables using bias-adjusted three-step approaches. Sociological Methodology 43 (1): 272-311.

Baldwin, P. 1990. The Politics of Social Solidarity: Class Bases of the European Welfare State, 18751975. Cambridge: Cambridge University Press.

Barr, N. 2001. The Welfare State as Piggy Bank: Information, Risk, Uncertainty and the Role of the State. Oxford: Oxford University Press.

Blalock, H.M. 1967. Toward a Theory of Minority-group Relations. New York: Wiley.

Blekesaune, M., and J. Quadagno. 2003. Public attitudes toward welfare state policies: A comparative analysis of 24 nations. European Sociological Review 19 (5): 415-427.

Bonoli, G. 2006. New social risks and the politics of post-industrial social policies. In Adapting Post-War Social Policies to New Social Risks, ed. K. Armingeon and G. Bonoli, 3-26. London: Routledge.

Borjas, G.J. 1999. Immigration and welfare magnets. Journal of Labor Economics 17 (4): 607-637.

Breznau, N., and M.A. Eger. 2016. Immigrant presence, group boundaries, and support for the welfare state in Western European societies. Acta Sociologica 59 (3): 195-214.

de Beer, P., and F. Koster. 2009. Sticking Together or Falling Apart: Solidarity in an Era of Individualization and Globalization. Amsterdam: Amsterdam University Press.

Cappelen, C., and Y. Peters. 2018. The impact of intra-EU migration on welfare chauvinism. Journal of Public policy 38 (3): 389-417.

Coser, L.A. 1956. Functions of social conflict. New York: The Free Press.

Crepaz, M.M.L., and R. Damron. 2009. Constructing tolerance: How the welfare state shapes attitudes about immigrants. Comparative Political Studies 42 (3): 437-463.

Eger, M.A., and N. Breznau. 2017. Immigration and the welfare state: A cross-regional analysis of European welfare attitudes. International Journal of Comparative Sociology 58 (5): 440-463.

Emmenegger, P., and R. Klemmensen. 2013. Immigration and redistribution revisited: How different motivations can offset each other. Journal of European Social Policy 23 (4): 406-422.

Feldman, S., and M.R. Steenbergen. 2001. The humanitarian foundation of public support for social welfare. American Journal of Political Science 45 (3): 658-677.

Finch, W.H., and B.F. French. 2014. Multilevel latent class analysis: Parametric and nonparametric models. The Journal of Experimental Education 82 (3): 307-333.

Gilens, M. 1999. Why Americans Hate Welfare: Race, Media, and the Politics of Antipoverty Policy. Chicago: University of Chicago Press.

Goodhart, D. (2004). Is Britain Too Diverse to Sustain the Mutual Obligations behind a Good Society and the Welfare State? Prospect Magazine.

Gorodzeisky, A., and M. Semyonov. 2009. Terms of exclusion: Public views towards admission and allocation of rights to immigrants in European countries. Ethnic and Racial Studies 32 (3): 401-423.

Hagenaars, J.A., and A.L. McCutcheon, eds. 2002. Applied Latent Class Analysis. Cambridge, UK: Cambridge University Press.

Koning, E. A. (2013). Selective Solidarity: The politics of immigrants' social rights in Western welfare states. Doctoral thesis, Queens University, Ontario, Canada. Retrieved from https://qspace.libra ry.queensu.ca/\%0Abitstream/1974/7922/1/Koning_Edward_A_201304_PhD.pdf

Kankaraš, M., G. Moors, and J. Vermunt. 2010. Testing for measurement invariance with latent class analysis. In Cross-cultural analysis: Methods and applications, ed. E. Davidov, P. Schmidt, and J. Billiet, 359-384. New York: Routledge.

Kulin, J., M.A. Eger, and M. Hjerm. 2016. Immigration or welfare? The progressive's dilemma revisited. Socius Sociological Research for a Dynamic World 2: 1-15.

Kymlicka, W. 2015. Solidarity in diverse societies: beyond neoliberal multiculturalism and welfare chauvinism. In Minorities and populism - critical perspectives from South Asia and Europe. Philosophy and politics—critical explorations, vol. 10, ed. V. Kaul and A. Vajpeyi, 41-62. Cham: Springer.

Kymlicka, W., and K. Banting. 2006. Immigration, Multiculturalism, and the Welfare State. Ethics and International Affairs 20 (3): 281-304.

McLachlan, G., and D. Peel. 2000. Finite mixture models. Hoboken, NY: Wiley.

Magidson, J., and J.K. Vermunt. 2001. Latent class factor and cluster models, Bi-plots, and related graphical displays. Sociological Methodology 31 (1): 223-264.

Mau, S., and C. Burkhardt. 2009. Migration and welfare state solidarity in Western Europe. Journal of European Social Policy 19 (3): 213-229. 
Meuleman, B., E. Davidov, and J. Billiet. 2009. Changing attitudes toward immigration in Europe, 20022007: A dynamic group conflict theory approach. Social Science Research 38 (2): 352-365.

Mewes, J., and S. Mau. 2013. Globalization, socio-economic status and welfare chauvinism: European perspectives on attitudes toward the exclusion of immigrants. International Journal of Comparative Sociology 54 (3): 228-245.

Newton, K. (2007) The New Liberal Dilemma: Social Trust in Mixed Societies. Paper Prepared for the ECPR Workshop on Social Capital, The State and Diversity, (May), 7-12.

Nylund, K.L., T. Asparouhov, and B.O. Muthén. 2007. Deciding on the number of classes in latent class analysis and growth mixture modeling: A Monte Carlo simulation study. Structural Equation Modeling 14 (4): 535-569.

Reeskens, T., and W. van Oorschot. 2012. Disentangling the 'New Liberal Dilemma': On the relation between general welfare redistribution preferences and welfare chauvinism. International Journal of Comparative Sociology 53 (2): 120-139.

Rights, J.D., and S.K. Sterba. 2016. The relationship between multilevel models and non-parametric multilevel mixture models: Discrete approximation of intraclass correlation, random coefficient distributions, and residual heteroscedasticity. British Journal of Mathematical and Statistical Psychology 69 (3): 316-343.

Robinson, R.V., and W. Bell. 1995. Equality, success, and social justice in England and the United States. American Sociological Review 43 (2): 125-143.

Roosma, F., J. Gelissen, and W. van Oorschot. 2012. The multidimensionality of welfare state attitudes: A European Cross-National Study. Social Indicators Research 113 (1): 235-255.

Senik, C., H. Stichnoth, and K. Van der Straeten. 2009. Immigration and natives' attitudes towards the welfare state: Evidence from the European Social Survey. Social Indicators Research 91 (3): 345-370.

Steele, L.G. 2016. Ethnic diversity and support for redistributive social policies. Social Forces 94 (4): 1439-1481.

Swaan, A.. De.. 1992. Perspectives for transnational social policy. Government and Opposition 27 (1): 33-51.

Taylor-Gooby, P., ed. 2004. New risks, new welfare: The transformation of the European welfare state. Oxford: Oxford University Press.

van Der Waal, J., W. De Koster, and W. Van Oorschot. 2013. Three worlds of welfare Chauvinism? How welfare regimes affect support for distributing welfare to immigrants in Europe. Journal of Comparative Policy Analysis: Research and Practice 15 (2): 164-181.

van Oorschot, W. 2006. Making the difference in social Europe: Deservingness perceptions among citizens of European welfare states. Journal of European Social Policy 16 (1): 23-42.

van Oorschot, W., and B. Meuleman. 2012. Welfarism and the multidimensionality of welfare state legitimacy: Evidence from The Netherlands, 2006. International Journal of Social Welfare 21 (1): 79-93.

van Oorschot, W., and W. Uunk. 2007. Welfare spending and the public's concern for immigrants: Multilevel evidence for eighteen European countries. Comparative Politics 40 (1): 63-82.

Vermunt, J.K. 2003. Multilevel latent class models. Sociological Methodology 33 (1): 213-239.

Vermunt, J.K. 2008. Latent class and finite mixture models for multilevel data sets. Statistical Methods in Medical Research 17 (1): 33-51.

Vermunt, J.K., and L.A. van Dijk. 2001. A nonparametric random-coefficients approach: The latest class regression model. Multilevel Modelling Newsletter 13 (2): 6-13.

Publisher's Note Springer Nature remains neutral with regard to jurisdictional claims in published maps and institutional affiliations. 


\section{Affiliations}

\section{Dimitri Gugushvili ${ }^{1} \cdot$ Laura Ravazzini $^{2,3}$ (D) Michael Ochsner ${ }^{5,6} \cdot$ Martin Lukac $^{4}$.} Orsolya Lelkes $^{7} \cdot$ Marcel Fink $^{8} \cdot$ Peter Grand $^{8} \cdot$ Wim van Oorschot $^{9}$

1 Centre for Sociological Research (CESO), Team Social Policy and Social Work, KU Leuven, Leuven, Belgium

2 NCCR, University of Neuchâtel, fbg. de l'Hôpital 27, 2000 Neuchâtel, Switzerland

3 Swiss Federal Statistical Office, Neuchâtel, Switzerland

4 Department of Methodology, London School of Economics and Political Science, London, United Kingdom

5 FORS, The Swiss Centre of Expertise in the Social Sciences, Lausanne, Switzerland

6 ETH Zurich, Zurich, Switzerland

7 Soziokratie Zentrum, Vienna, Austria

8 Institute for Advanced Studies, Wien, Austria

9 Faculty of Social Sciences, KU Leuven, Leuven, Belgium 